trated solution; others gave negative osmose; the direction of flow in these unusual cases was from the concentrated to the more dilute solution.

2. Cells were set up with pure water inside and salt solutions outside. When set up in this reversed manner, the solutions which had previously given decreased pressure within the cells now gave increased pressure, that is, the direction of flow was from concentrated to dilute solution even though opposed by hydrostatic pressure.

3. The quantities of the salts which diffused through the membranes were determined. It was found that the order of diffusion quantities of the salts through the porcelain membranes is practically the same as the order of diffusion velocities when no membrane is present. Also it was found that the membranes which have the greatest negative osmose through them have, on the other hand, the smallest quantities of salts diffusing through them.

4. The flow of the solution as a whole through the membrane, in all the experiments with the nitrates and chlorides, was toward the more dilute solution, provided the anion had a somewhat greater migration velocity than the cation; also the greater the difference between the migration velocities of anion and cation the greater the rate of flow.

5. It has been shown that the appearance of negative osmose is dependent on the pore diameter of the membrane. Negative osmose of $\mathrm{MgCl}_{2}$ in neutral solution, and with porcelain membranes, predominates only when the pore diameters are somewhat less than 0.4 micron.

6. The facts brought out in this investigation seem to indicate that negative osmose is dependent on the electrical polarization of the capillaries of the membrane, also it seems probable that this polarization is largely brought about through ionic adsorption by the membrane.

UNIVERSITY OF MrCHIGAN,

ANN ARBOR, MICH.

\title{
NOTE.
}

Convenient Standard End Point in the Titration of Alkali Carbonates with Hydrochloric Acid.-As long ago as I 897, Küster $^{1}$ pointed out that, in the titration of sodium carbonate against hydrochloric acid, when equivalent amount of acids and base have been used, the solution contains free carbonic acid, and that this acid exerts an appreciable effect on the color of an aqueous solution of methyl orange. A tenth normal solution of carbonic acid, which results from titration with fifth normal solutions, is a little more than saturated with carbon dioxide at $20^{\circ}$.

Küster recommends adjusting the color of the solution obtained in titration to that of a saturated aqueous solution of carbon dioxide containing methyl orange. Unfortunately, this standard end point is not permanent, even in corked vessels, owing probably both to the escape of carbon dioxide

${ }^{1}$ Z. anorg. Chem., I3, I4I (1897). 
and to the solubility of the alkaline constituents of the glass, and hence it must frequently be renewed. A similar color with methyl orange obviously may be produced by aqueous solutions of other acids or acid salts of suitable concentration. Of these, monopotassium and monosodium phosphate are particularly well adapted for the purpose, since the acidity of solutions of these substances is affected relatively slowly by the addition of acids or alkalies. Although the dissociation constant of the second hydrogen of phosphoric acid, $2 \times 10^{-7}$, is nearly identical with that of the first hydrogen of carbonic acid, $3 \times \mathrm{IO}^{-7}$, the acidity of a solution of monosodium phosphate is somewhat less than that of an equivalent solution of carbonic acid, owing possibly to hydrolysis. Comparison of the color of a saturated aqueous solution of carbon dioxide, containing methyl orange, and solutions of monosodium phosphate of various concentrations, also containing methyl orange, shows that the carbonic acid solution is perceptibly less acid than a phosphate solution containing $20 \mathrm{~g}$. of crystals ${ }^{1}$ in $100 \mathrm{~g}$. of water, more so than one containing $15 \mathrm{~g}$. of crystals in $100 \mathrm{~g}$. of water, while a solution of $17.5 \mathrm{~g}$. of crystals in roo $\mathrm{g}$. of water possesses apparently the same color as the carbonic acid solution. An equivalent solution of monopotassium phosphate, containing $15.3 \mathrm{~g}$. of crystals ${ }^{2}$ was found to be identical in color with the solutions of the sodium salt. Since the hydrogen ion concentration of a carbonic acid solution changes only from about 2.5 $\times \mathrm{IO}^{-4}$ to $\mathrm{I.2} \times 1 \mathrm{10}^{-4}$ between the limits of 0.2 normal and 0.05 normal, and since this difference in the hydrogen ion concentration corresponds to only $0.06 \mathrm{cc}$. fifth normal hydrochloric acid in roo cc., and since, by escape of carbon dioxide, more concentrated solutions tend to approach a concentration of tenth normal, it is obvious that the above end point can safely be used in the titration of solutions from half to tenth normal.

Before being used, both salts should be crystallized to free them from phosphoric acid or disodium phosphate. Owing to its lesser solubility, the potassium salt is somewhat more easily purified and therefore better adapted for the purpose. ${ }^{3}$

Gregory Paul Baxter.

T. JEFFERSON COOLIDGE MEMORIAL LABORATORY,

Harvard University, Cambridge, Mass.

\section{OBSERVATIONS ON SOME BARBIER-GRIGNARD REACTIONS.}

BY L. P. KYRIAKIDES.

Received February 2, 1914.

Methylethylethylene chlorhydrin: Chloro - I - methyl - 2 - butanol - 2, $\mathrm{CH}_{3} \cdot \mathrm{CH}_{2} \cdot \mathrm{C}\left(\mathrm{CH}_{3}\right)(\mathrm{OH}) \cdot \mathrm{CH}_{2} \mathrm{Cl}$. - The chlorhydrins are usually obtained by the addition of hypochlorous acid to the unsaturated hydrocarbons.

${ }^{1} \mathrm{NaH}_{2} \mathrm{PO} .2 \mathrm{H}_{2} \mathrm{O}$. This hydrate crystallizes between $4 \mathrm{I}^{\circ}$ and $0^{\circ}$. Imadsu, Mem. Coll. Sci. Eng. Kyoto Imp. Univ., 3, 257 (1912).

${ }^{2} \mathrm{KH}_{2} \mathrm{PO}_{4}$.

This was pointed out to me by Dr. H. H. Willard. 